\title{
Retraction Note To: VEGF Silencing Inhibits Human Osteosarcoma Angiogenesis and Promotes Cell Apoptosis via PI3K/AKT Signaling Pathway
}

\author{
Jian Zhao ${ }^{1} \cdot Z_{\text {Zi-Ru Zhang }}{ }^{1} \cdot$ Na Zhao $^{2} \cdot$ Bao-An Ma $^{1} \cdot$ Qing-Yu Fan $^{1}$
}

Published online: 17 April 2017

(C) Springer Science+Business Media New York 2017

\section{Retraction Note to: Cell Biochem Biophys (2015) 73:519-525 \\ DOI 10.1007/s12013-015-0692-7}

Due to dual submission, the Editor in Chief of CBBI wishes to retract this article: Zhao, J., Zhang, Z.R., Zhao, N., Ma, B.A., Fan, Q.Y. (2015). VEGF silencing inhibits human osteosarcoma angiogenesis and promotes cell apoptosis via PI3K/AKT signaling pathway. Cell
Biochemistry Biophysics, 73(2), 519-25. Doi:10.1007/ s12013-015-0692-7.

This article was also published as:

Zhao, J., Zhang, Z.R., Zhao, N., Ma, B.A., Fan, Q.Y. (2015). VEGF silencing inhibits human osteosarcoma angiogenesis and promotes cell apoptosis via PI3K/AKT signaling pathway. International Journal of Clinical and Experimental Medicine, 8(8), 12411-12417.

The online version of the original article can be found under doi:10. 1007/s12013-015-0692-7.

Qing-Yu Fan

drfanqingyu01@163.com

1 Department of Orthopedic Surgery, Tangdu Hospital, Orthopedics Oncology Institute of Chinese PLA, Fourth Military Medical

University, No. 569 XinSi Road, Xi'an, Shanxi Province 710038, People's Republic of China

2 Outpatient Department, Tangdu Hospital, Fourth Military Medical University, Xi'an, Shanxi Province 710038, People's Republic of China 